\title{
The Impact of Organizational Health on Student Achievement in a High Needs District
}

\author{
Roberto Zamora, Ph.D. \\ The University of Texas Rio Grande Valley \\ 1401 West University Drive \\ Edinburg, TX 78539 \\ 956.458 .5754 \\ E-mail: roberto.zamora@utrgv.edu \\ Rosalinda Hernandez, Ph.D. \\ The University of Texas Rio Grande Valley \\ 956.225 .8388 \\ E-mail: rosalinda.hernandez@utrgv.edu
}

Received: May 22, 2016 Accepted: July 15, 2016 Published: August 1, 2016

doi:10.5296/jse.v6i3.9904 URL: http://dx.doi.org/10.5296/jse.v6i3.9904

\begin{abstract}
This study establishes the relationship between organizational health and student achievement in English Language Arts and Mathematics in grades 3-11. The purpose of this quantitative study was to assess the relationship between student achievement as measured by student performance in the State of Texas Assessment of Academic Readiness and organizational health. The Spearman Rho correlation coefficient was computed to determine the strength of the relationships between student achievement and the ten dimensions of organizational health. The findings indicated there was a positive relationship between student performance and the dimensions of organizational health with morale and goal focus exhibiting the greatest strengths.
\end{abstract}

Keywords: organizational health, dimensions, accountability, school culture, organizational culture 
A national call for improving student achievement is exerting tremendous pressure on school leaders and teachers. This emphasis on student achievement has been magnified as a result of an increase in rigor of state curricula and the high stakes state and federal accountability systems which are directly linked to student performance on state assessments. Historically, test results have revealed an achievement gap exists between economically disadvantaged and non-economically disadvantaged students. The No Child Left Behind (NCLB) Act, enacted in 2001, required states to make verifiable gains in student achievement and to close the achievement gap between economically disadvantaged and non-economically disadvantaged students (NCLB, 2001). Both state and federal accountability systems require that all students be assessed in reading and mathematics. States are also required to set performance standards and apply assessment results to determine effectiveness of schools and districts (Texas Education Agency, 2014; NCLB, Sec 1111. State Plans (b) Academic Standards, Academic Assessments, and Accountability, (2001). These campus and district ratings are made public with considerations given to diverse needs of students or other factors experienced by districts. Moreover, policymakers expect school leaders to create a learning environment in which achievement gaps are closed between diverse groups of students (Thernstrom, 2003). Emphasis on assessment and accountability will continue under the Every Student Succeeds Act (ESSA, 2015). States will be required to assess students in mathematics and reading or language arts in each of grades 3-8 mathematics and least once in grades 9-12. Results will need to be reported to the public for each of the following subgroup of students: economically disadvantaged, major racial and ethnic groups, English Language Learners and children with disabilities (ESSA, Sec. 1111. State plans 2015).

To add to the discourse of student achievement, organizational health has reemerged as a contributing factor that impacts student learning (Fairman, 2011; Roney, 2011; Uline, 1998; Hoy, 1997). The concept of organizational health as applied to schools was first introduced by Matthew Miles (1965) when he wrote the Change Process in Public Schools. At that time, he stated "It is time for us to recognize that successful efforts at planned change must take as a primary target the improvement of organizational health - the school system's ability not only to function effectively, but to grow into a more fully - functioning system" (pp. 11-12). Hoy's (1991) research and Fairman's (2014) work have provided evidence that supports the importance of organizational health in improving student achievement. Other researchers have supported that the school learning environment is affected by the school learning climate, school culture and organizational health (Roney, 2011; Barth, 2001; Uline, 1998; Hoy, 1990). Schools have focused on what they know about the curricular and instructional methods of educating the populous; however, a factor seldom considered as a contributing factor towards student achievement is the health of the organization. Could it be that schools have notoriously used only student performance data to determine the success of a school and organizational health has languished due to a lack of understanding on how to measure and support the health of the organization? The study of organizational health in public schools proposes new insights and challenges for educators. It adds focus to the affective domain andthe importance ofschool practices and processes which impact the schools' organizational health and their capacity to adapt and respond to increasing learning standards and diverse student learning needs. This study establishes the relationship between organizational health and student achievement in the 
areas of English Language Arts (Reading) and mathematics in grades 3-11 based on a state assessment.

\section{Theoretical Framework}

As social systems, schools are continuously impacted by what happens in their internal and external environments. Changes in both environments exert pressures on schools to adapt or change over time. How well a school accepts the need for change and adapts to a different set of conditions and expectations affects the outcomes it attains (Hoy \& Miskel, 2001; Argyris, 1990; Bennis, 1966).Changing student demographics, coupled with increasing learning standards, require that schools intentionally assess and adapt their practices. The call for schools to adapt and become more responsive to diverse learner needs is not a recent admonition. Matthew Miles (1966) wrote "schools must accept children of a very wide range of ability and motivation to carry out goals as well as academic learning goals" (p. 24).

To address these needs, the researchers turned to the seminal work of Matthew Miles (1965) on Planned Change and Organizational Health and the work done nationally, over the last three decades, by Fairman and McLean (2011) to enhance school organizational health and leadership effectiveness. The researchers used Fairman and McLean's Model on Sustained Systemic Success, illustrated in Figure 1 below, which employs the school's organizational health dimensions as essential components for improving student achievement.

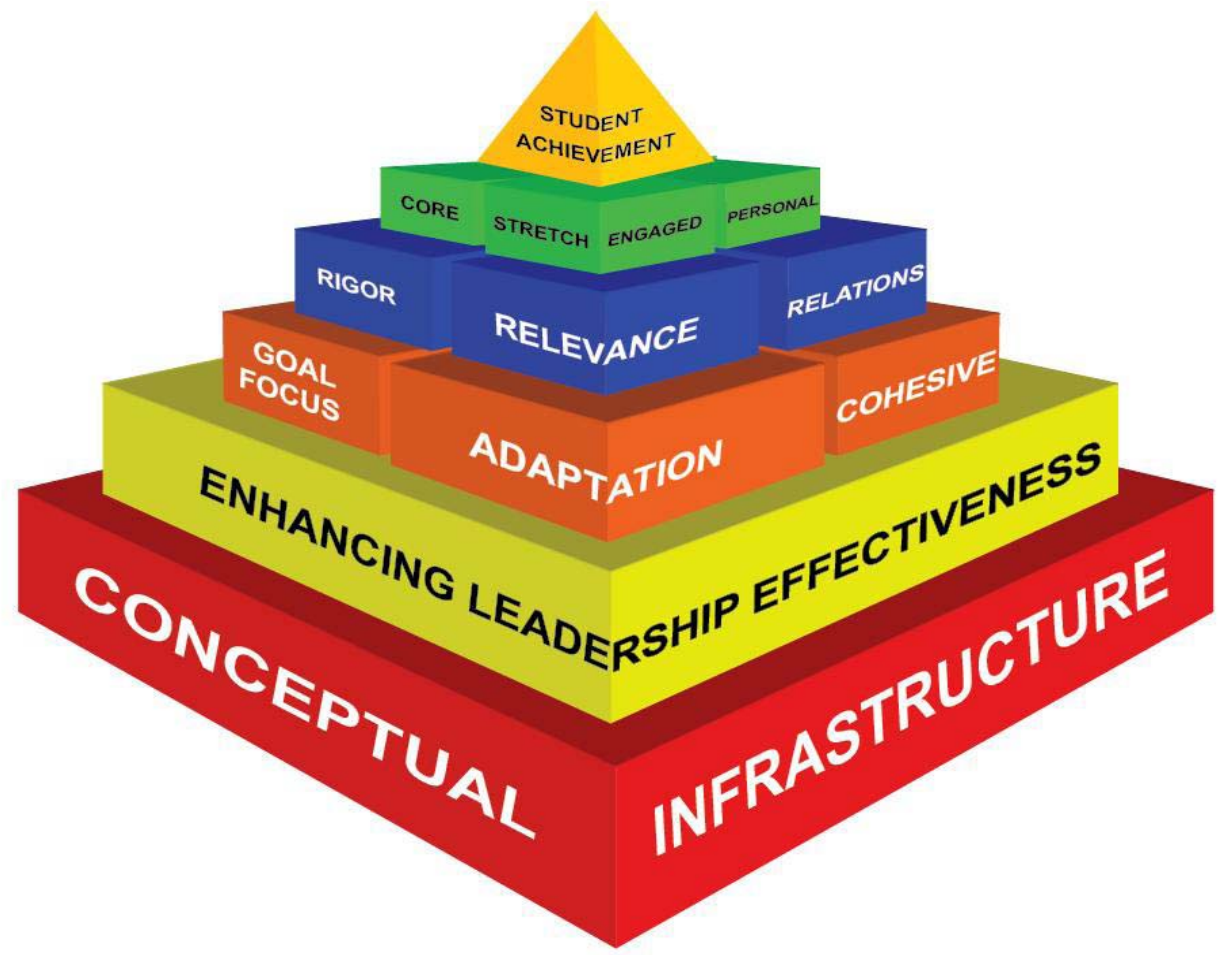

Figure 1. Sustained Systemic Success Model ${ }^{\mathrm{TM}}$, Enhancing Leadership Effectiveness, Fairman and McLean (2014)

Fairman and McLean's (2014)conceptual model for enhancing student achievement is composed of six interdependent tiers. The first tier of the pyramid represents the organizational 
health principles and beliefs. Coupled with the vision and mission, these provide the foundation upon which all other tiers are built. The second tier, enhancing leadership effectiveness, emphasizes the importance of leadership. Fairman and McLean use Hershey and Blanchard's Situational Leadership concepts and Covey's Maturity Continuum development concept as the underpinning for enhancing leadership capacity and organizational productivity. The third tier represents the ten dimensions of organizational health. Goal Focus, Adaptation, and Cohesiveness appear in the forefront because these three dimensions have been shown, by Fairman and McLean, to have the highest correlation to student achievement. The ten dimensions of organizational health are based on Matthew Miles' (1965) research on this topic. The fourth tier represents the importance of quality instruction characterized by rigor and relevance and for building quality relationships. The fifth tier focuses on the curricula. The core and stretch (essential and enriched/extended) curriculum fosters on student engagement and personal skill development. The sixth tier, student achievement, spotlights the culminating effects of all tiers acting interdependently to promote student achievement and sustained systemic success.

Fairman and McLean (2014) analyze the organizational health of a school by applying the ten dimensions proposed by Matthew Miles (Fairman, 2011, 2014; Miles, 1965). Fairman and McLean define organizational health as "an organization's ability to function effectively, to cope adequately, to change appropriately, and to grow from within" (Fairman, 2011, p. 94). The dimensions and definitions follow.

Goal Focus: The ability of persons, groups, or organizations to have clarity, acceptance, support, internalization, and advocacy of goals and objectives.

Communication Adequacy: The state which exists when information is relatively distortion free and travels both vertically and horizontally across the boundaries of an organization.

Optimal Power Equalization: The ability to maintain a relatively equitable distribution of influence between leaders and team members.

Resource Utilization: The ability to coordinate and maintain inputs, particularly personnel, effectively with a minimal sense of strain.

Cohesiveness: The state in which a person, group, or organization have feelings of well-being, satisfaction, and pleasure.

Morale: The state in which a person, group, or organization have feelings of well-being, satisfaction, and pleasure.

Innovativeness: The ability to be and allow others to be inventive, diverse, creative and risk-taking.

Autonomy: The state in which a person, group, or organization have the freedom to fulfill their roles and responsibilities.

Adaptation: The ability to tolerate stress and maintain stability while coping with demands of the environment. 
Problem Solving Adequacy: The ability of an organization to perceive problems and solve them with minimal energy. The problems stay solved and the problem solving mechanism of the organization is maintained and/or strengthened (Fairman, 2011, pp. 94-95).

The organizational health component of Fairman and McLean's (2014) Sustained Systemic Success Model ${ }^{\mathrm{TM}}$ guided the researchers through this study. Important concepts embedded in the Sustained Systemic Success Model are organization culture, school culture, and organizational health. These concepts are explained in the following literature review.

\section{What is Organizational Culture?}

Organizational culture has become a central concern in the study of organizational behavior and it has not been limited to academia. Businesses expressed an interest in culture that was far more intense than their concern with other aspects of organizational behavior. Another impetus for the study of organizational culture came from the realization by a number of people in the 1970s that traditional, organizational approaches were not as useful as they might have been in leading to an understanding of observed disparities between organizational goals and outcomes, or between strategy and implementation (Ouchi \& Wilkins, 1985). According to Hoy and Miskel (1991), the notion of culture resurfaced as a vehicle for understanding the meaning and basic character of organizational life. They state that in the past, both Elton Mayo (1945) and Chester Barnard (1938) were stressing the importance of work-group norms, sentiments, values, and functions of organizations. This general line of reasoning began to suggest that organizational models were incomplete without inclusion of cultural aspects.

It is not surprising, then, to see the rediscovery of the culture concept when excellence tends to be defined in terms of what the organizations do and how they behave. According to Conway (1985), "this is consistent with the earliest days of anthropology when Tyler defined culture as that complex whole which includes knowledge, belief, art, morals, law, custom, and any other capabilities and habits acquired by men as a member of society" (p. 8 ). Conway further stated that the essence of that definition is still found in the more recent applications of organizational culture. For example, Stonich (1982, p. 35) describes culture as:

A pattern of beliefs and expectations shared by members of an organization. These beliefs and expectations produce rules for behavior - norms - that powerfully shape the behavior of individuals and groups in the organization. Just as individuals in a culture can have different personalities while sharing much in common, so too with groups and organizations.

Pettigrew (1979) recognized the more diversified nature of the concept of culture by adding to the content the events that make culture visible. He further stated that "while providing a general sense of orientation, culture treated as a unitary concept in this way lacks analytical bite. A potentially more fruitful approach is to regard culture as the source of a family of concepts" (p. 34). Emphasis has been on the ideological content, i.e., the beliefs and values of the organization as these manifest through examination of the tools, symbols, customs, rites, and language. In the same manner, the organization's culture becomes more evident through 
heroes of the organization who exemplify the organizations values, beliefs and expectations and serve as role models for others(Deal \& Kennedy, 1992).

Most definitions of organizational culture include values, symbols, and other factors that communicate the culture to employees (Moorhead \& Griffin, 1992). Deal and Kennedy (1992, p. 4) define a firm's culture as "the way we do things around here." More specific definitions include those by Schein (1983) who defines the culture of an organization as the "the pattern of basic assumptions that a given group has invented, discovered, or developed in learning to cope with its problems of external adaptation and internal integration" (p.14). Schein (2010) later expressed that the culture of an organization is all the beliefs, feelings, behaviors, and symbols that are characteristic of an organization and more specifically, organizational culture is defined as shared philosophies, ideologies, beliefs, feelings, assumptions, expectations, attitudes, norms, and values.

Moorhead and Griffin (1992) point out three common attributes emerge in defining organizational culture. First, all definitions refer to some set of values held by individuals in an organization. Next, values that make up an organization's culture often are taken for granted - that is rather than being written in a book or made explicit in a training program, they are basic assumptions made by the organization's employees. The final attribute places an emphasis on symbolic means through which the values in an organization's culture are communicated (Moorhead \& Griffin).

\section{What is School Culture?}

School administrators grapple with the need to improve students' academic achievement to attain the highest marks in state accountability systems. Change in the schools has been primarily around instructional change to improve student achievement. Analogous to the business focus that culture is an important factor for performance gains, public schools have determined that their solutions are not only about instructional change but about the focus on the school's culture (Gonder, 1994). The realization that the school's culture can either impede or support learning has caused a renewed interest in how one focuses and changes school culture (Tableman, 2004). According to Tableman, "school culture is the shared beliefs and attitudes that characterize the district-wide organization and establish boundaries for its constituent units" (p. 1). Tableman goes on to say that school culture "reflects the shared ideas-assumptions, values and beliefs-that give an organization its identity and standard for expected behaviors" (p.1).

Schein (1985) proposes in his book, Organizational Culture and Leadership, culture should be about the deeper level of basic assumptions and beliefs that are shared by members of an organization in which people operate unconsciously.

\section{What is Organizational Health?}

The concept of organizational health evolved as researchers and theorists examined organizations as open systems and grappled with the task of identifying criteria to determine the effectiveness of organizations. The need to view organizations as open systems was 
voiced by Chris $\operatorname{Argyris}(1964,1990)$. He contended that this was needed because organizations are influenced by the environment in which they exist.

Similarly, Warren Bennis (1966) voiced that organizations must be "viewed as adaptive, problem solving, organic structures" (p. 43). How the organization searches for, adapts to, and problem solves its goals pawned the critical dimensions of organizational health. Bennis identified three criteria for determining organizational health: adaptability, identity, and reality testing. Adaptability corresponds to the organization's problem solving ability and flexibility. Flexibility denotes the freedom to learn and change in response to changes in the internal and external environments. Identity refers to the extent to which the organization knows its mission. Reality testing calls attention to the need for organizations to "develop adequate techniques for determining the 'real properties' of the field in which it exists" (Bennis, p.54).

Miles (1965) described schools as open systems which receive inputs from their environments and produce outputs as a result of the processes and interactions of the various system structures and "social psychological components" that operate interdependently. One condition of open systems is organizational health which is comprised of ten dimensions that "are not, of course, mutually exclusive, but interact with each other vigorously within any particular organization" (p. 18). Milescon structured an organizational health framework which grouped the ten dimensions, based on their function, into three needs categories: task-centered, maintenance needs, and growth and changefulness. The task-centered dimensions include goal focus, communication adequacy and optimal power equalization. These dimensions focus on goal attainment, information flows across the organization, and the extent to which leaders share power with staff. The maintenance needs dimensions are resource utilization, cohesiveness, and morale. These dimensions address how personnel are utilized to maximize productivity, how individuals work with each other, and how individuals feel about being a member of the organization. The growth and changefulness dimensions include innovativeness, autonomy, adaptation and problem solving. These dimensions pertain to the organization's capacity to grow from within, to change in response to inputs received from its environment, and to cope with, respond to, and solve problems. Miles' three needs categories are analogous to the three organizational health criteria postulated by Bennis (1966) - adaptability, identity, and reality testing. The compelling premise for both Miles and Bennis is that organizations must maintain focus on their goals, respond to environment changes, and adapt and develop over time.

Healthy organizations effectively respond to their environments and continue to adapt and develop amidst challenges that may arise. Unhealthy organizations are less apt to cope with emerging challenges; hence, they will become less productive and decline overtime. Healthy organizations proactively act to remain effective. As is true for personal health, the greater the challenge experienced, the healthier an organization must be to effectively respond to increasingly challenging requirements (Hoy, 1991).

Wayne K. Hoy (1991) has done extensive work pertaining to organizational health and school climate. Initially, he experienced difficulty in operationalizing Miles' dimensions of 
organizational health. As a result, he referred to Talcott Parsons analysis of social systems functions and levels of control (Hoy, 1991) and Amitai Etzioni's (1975) classification of activities required for an organization to effectively adapt to its environment and attain its goals.

Talcot Parsons identified four system functions: goal attainment, adaptation, integration, and latency(Black, 1961). Goal attainment refers to actions the system takes to accomplish its goals. Adaptation refers to changes the system takes to survive and attain its goals in response to its environment. Integration refers to the relationships that exist between different parts of the systems and their level of cohesiveness. Latency refers to actions required to keep the system moving towards its goals. The expectation is that the system be able to effectively respond to changes in its environment.

In addition to the Parsons (1967) identified three hierarchical levels of control in organizational structures: technical, managerial and institutional. He explained how these levels apply in educational organizations. In schools, technical levels pertain to the process of teaching; managerial levels refer administrative processes and controls needed for operate and coordinate the school's functions; and the institutional level links the schools to its external environment and stakeholders such as the school board, community, businesses and other agencies.

Etzioni (1975) classified organizational activities into two categories: instrumental and expressive. In their research, Uline, Miller \&Tschenan-Moran (1998) referred to the instrumental category as actions by which a school considers and responds to inputs from its environment and expressive activities as actions that contribute to the development of the school culture. These activities foster clarification of the school's norms and values and promote collegiality.

Having considered Parson's and Etzioni's systems perspectives, Hoy (1991) defined a healthy school as being "one in which the technical, managerial, and institutional levels are in harmony and the school is meeting both its instrumental and expressive needs as it copes with disruptive external forces and directs its energies towards its mission" (p.68). As a result of their research and work, Hoy and his team developed Organizational Health Inventories (OHI) to assess the organizational health of elementary, middle and high schools. Hoy's Organizational Health Inventory differs from the Organizational Health Inventory developed by Marvin Fairman and his Associates. Extensive research has been conducted using Hoy's OHI. Limited research using Fairman's OHI to determine relationship between organizational health and student achievement is found in the literature. However, in work done with school districts across the country over the last three decades, Fairman and McLean have consistently found a relationship between organizational health and student achievement (Fairman, 2011). This study will contribute empirical evidence pertaining to the relationship between student achievement in English language arts (reading) and mathematics and the ten dimensions of organizational health and total organizational health. The research questions that guided this study follow.

1. Is there a relationship between Reading achievement and each of the 10 dimensions of 
Organizational Health and the Total Organizational Health score?

2. Is there a relationship between Math achievement and each of the 10 dimensions of Organizational Health and the Total Organizational Health score?

3. Is there a relationship between Reading and Math achievement combined and each of 10 dimensions of Organizational Health and the Total Organizational Health score?

\section{Methodology and Research Design}

The purpose of this quantitative study was to assess the relationship between student achievement, as measured by student performance in the State of Texas Assessment of Academic Readiness (STAAR) and organizational health. The population sample consisted of36 elementary, middle and high schools. Based on Texas Education Agency data all participating schools were Title I schools with approximately 95\% economically disadvantaged student enrollment (TEA, 2013-2014 PEIMS Data).All schools mirror similar demographics: $97 \%-99.8 \%$ Hispanic. District wide $48 \%$ of the student were identified as English Language Learners (ELLs) and 70\% of the ELLs were enrolled in grades PK-5; 32\% were enrolled in grades 6-8; and 16\% were enrolled in grades $9-12$. The primary language of all ELLs was Spanish (TEA,2015).

Hypotheses for the study are listed below. The Spearman Rho statistical method was used to assess the correlation between student achievement and organizational health as indicated in Research Hyptheses $\mathrm{H}_{1} \cdot 1-\mathrm{H}_{1} .4$. The strength of the relationship was determined using a 1 -tailed $t$ distribution at the .05 level of significance.

$\mathrm{H}_{1} .1$ : There is a positive relationship between Reading achievement and each of the 10 dimensions of Organizational Health and the Total Organizational Health score?

$\mathrm{H}_{0}$.1: There is no relationship between Reading achievement and each of the 10 dimensions of Organizational Health and the Total Organizational Health score?

$\mathrm{H}_{1} .2$ : There is a positive relationship between Math achievement and each of the 10 dimensions of Organizational Health and the Total Organizational Health score?

$\mathrm{H}_{0} .2$ : There is no relationship between Math achievement and each of the 10 dimensions of Organizational Health and the Total Organizational Health score?

$\mathrm{H}_{1} .3$ : There is a positive relationship between Reading and Math achievement combined and each of 10 dimensions of Organizational Health and the Total Organizational Health score? $\mathrm{H}_{0} .3$ : There is no relationship between Reading and Math achievement combined and each of 10 dimensions of Organizational Health and the Total Organizational Health score?

\section{Data Sources and Collection Procedures}

Student performance data were acquired from the Texas Education Agency (TEA) 2015 Campus Accountability Summary Reports: State System Safeguards-Status Reports. Student performance data utilized for this study were the percent of students that met the state's Phase-in 
Satisfactory Standards in Reading and Mathematics. Total students passing reading and mathematics, by campus, were calculated by the researchers.

The percent of economically disadvantaged students enrolled at each campus was based on data available on the District's 2014 -2015 Texas Academic Performance Reports produced by the Texas Education Agency for each campus. These data represent the percent of students eligible to receive free or reduced lunch.

To measure organizational health, data were collected using an Organizational Health Instrument (OHI) created by Fairman and Associates. The OHI is "designed to measure the quality of the organizational environment and to capture some of the more subtle and complex internal systemic dynamics that improve productivity" (Fairman, 2014, p.8). The OHI is comprised of eight items per dimension for a total of eighty items. Respondents indicate their responses on a five point Likert type scale which includes: Strongly Agree, Agree, Undecided, Disagree and Strongly Disagree. Fairman and his associates developed the instrument after three years of rigorous research and field testing for validity and reliability. In the initial phase, field tests were conducted in two metropolitan school districts. In Phase Two, Forms A and B of the OHI were developed from the pool of items generated in Phase One. In Phase Three, the OHI was adapted for use in the business sector (Johnstone, 1988).

In practice, the $\mathrm{OHI}$ is used to measure perceptions of the members of an entire workgroup. Interpretation is based on the group mean ratings of the items within each dimension. Interpretation of the scores of individual workgroup members is not intended. Therefore, the measures of reliability of the OHI scales are based on group data when possible, to reflect the actual conditions of using the OHI (Johnstone, p. 5).

The matter of assessing the relationship between organizational health and student achievement was a determining factor in selecting Fairman's Model on Organizational Health. The OHI allows for confidential information to be gathered on the 10 dimensions that comprise organizational health. OHI results by dimension and Total $\mathrm{OH}$ scores for each campus were used in the analysis.

The survey was completed by teachers at elementary schools during a faculty meeting; middle schools and high school teachers completed the survey during a faculty meeting or during teacher planning periods. Instructions for administering and returning the completed Organizational Health Instruments were provided to the principal and to a faculty member elected by the faculty who was responsible for collecting and returning completed surveys, in a sealed envelope, to a central office location.

Principals were asked to establish the setting for completion of the survey. The following statement, an excerpt from instructions provided by the principal, provides a sense of the principal's message to the faculty:

We have chosen to use the Organizational Health Instrument as an objective way to gain your perceptions of the internal workings of our school. This process is designed to help us maintain and/or to establish a positive and productive working environment. Your feedback will assist us in utilizing our strengths as we identify and target organizational improvement priorities 
(Fairman, 2015, p.1).

The elected faculty member was responsible for reading instructions for completing thesurvey. To assure faculty that their responses would be confidential, the faculty representative communicated to faculty: "As the faculty representative, I will be responsible for placing all forms in the envelope, sealing the envelope, signing the form indicating that we have followed these procedures, and sending the completed packet to the specified address" (Fairman, 2015, p.2).When all surveys were completed the faculty representative sealed the envelope in the presence of other faculty members and hand delivered the completed OHIs to the designated district office.

\section{Findings}

The percentile scores for each of the ten dimensions and the total Organizational Health $(\mathrm{OH})$ scores are presented in Table 1. 
Table 1. Organizational Health Percentile Scores By Dimensions and Total Score per Campus

\begin{tabular}{|c|c|c|c|c|c|c|c|c|c|c|c|}
\hline CODE & GF & COM & OPE & RES & $\mathrm{COH}$ & MOR & INN & AUT & ADA & PSA & T OH \\
\hline 001 & 56 & 43 & 48 & 49 & 36 & 30 & 49 & 16 & 27 & 24 & 38 \\
\hline 002 & 10 & 6 & 9 & 7 & 3 & 12 & 7 & 13 & 7 & 6 & 8 \\
\hline 003 & 94 & 75 & 81 & 87 & 81 & 83 & 86 & 56 & 80 & 78 & 80 \\
\hline 004 & 80 & 59 & 43 & 61 & 34 & 54 & 34 & 32 & 53 & 67 & 52 \\
\hline 005 & 83 & 48 & 46 & 71 & 60 & 48 & 45 & 21 & 63 & 37 & 52 \\
\hline 006 & 99 & 92 & 92 & 95 & 89 & 92 & 88 & 71 & 84 & 93 & 89 \\
\hline 007 & 82 & 64 & 60 & 66 & 62 & 67 & 53 & 19 & 45 & 63 & 58 \\
\hline 008 & 42 & 33 & 19 & 34 & 29 & 33 & 26 & 9 & 18 & 28 & 27 \\
\hline 009 & 32 & 16 & 37 & 15 & 11 & 21 & 23 & 13 & 13 & 13 & 19 \\
\hline 010 & 41 & 35 & 35 & 37 & 38 & 41 & 37 & 19 & 37 & 33 & 35 \\
\hline 011 & 64 & 42 & 43 & 39 & 17 & 28 & 40 & 28 & 48 & 35 & 38 \\
\hline 012 & 80 & 70 & 51 & 70 & 43 & 59 & 48 & 19 & 51 & 62 & 55 \\
\hline 013 & 49 & 25 & 34 & 27 & 20 & 13 & 28 & 16 & 18 & 21 & 25 \\
\hline 014 & 65 & 71 & 62 & 54 & 52 & 61 & 55 & 30 & 50 & 57 & 56 \\
\hline 015 & 96 & 90 & 90 & 91 & 80 & 87 & 90 & 70 & 84 & 79 & 86 \\
\hline 016 & 78 & 69 & 70 & 74 & 54 & 71 & 64 & 46 & 54 & 52 & 63 \\
\hline 017 & 95 & 91 & 90 & 95 & 84 & 95 & 91 & 84 & 88 & 84 & 90 \\
\hline 018 & 42 & 45 & 39 & 43 & 48 & 48 & 38 & 19 & 28 & 33 & 38 \\
\hline 019 & 85 & 54 & 62 & 62 & 72 & 68 & 59 & 41 & 56 & 53 & 61 \\
\hline 020 & 70 & 76 & 63 & 45 & 59 & 65 & 59 & 32 & 32 & 34 & 54 \\
\hline 021 & 66 & 49 & 59 & 59 & 54 & 61 & 46 & 36 & 42 & 56 & 53 \\
\hline 022 & 53 & 51 & 44 & 52 & 42 & 48 & 45 & 27 & 40 & 41 & 44 \\
\hline 023 & 97 & 86 & 88 & 86 & 75 & 85 & 92 & 49 & 78 & 75 & 81 \\
\hline 024 & 51 & 42 & 29 & 41 & 25 & 38 & 31 & 14 & 21 & 31 & 32 \\
\hline 025 & 69 & 58 & 26 & 48 & 72 & 58 & 48 & 11 & 55 & 46 & 49 \\
\hline 026 & 45 & 32 & 41 & 50 & 30 & 63 & 38 & 39 & 38 & 32 & 41 \\
\hline 027 & 36 & 26 & 33 & 12 & 15 & 24 & 13 & 10 & 14 & 12 & 20 \\
\hline 028 & 69 & 49 & 34 & 43 & 19 & 50 & 29 & 16 & 17 & 33 & 36 \\
\hline 029 & 99 & 99 & 99 & 99 & 99 & 99 & 99 & 99 & 99 & 99 & 99 \\
\hline 030 & 90 & 75 & 69 & 76 & 72 & 84 & 87 & 71 & 74 & 71 & 77 \\
\hline 031 & 59 & 47 & 29 & 38 & 31 & 42 & 20 & 19 & 26 & 37 & 35 \\
\hline 032 & 88 & 74 & 67 & 81 & 68 & 76 & 77 & 48 & 61 & 65 & 70 \\
\hline 033 & 85 & 30 & 28 & 62 & 46 & 45 & 41 & 15 & 36 & 51 & 44 \\
\hline 034 & 93 & 83 & 86 & 62 & 67 & 87 & 77 & 61 & 66 & 72 & 76 \\
\hline 035 & 77 & 53 & 53 & 71 & 64 & 64 & 56 & 51 & 66 & 55 & 61 \\
\hline 036 & 89 & 58 & 49 & 73 & 54 & 61 & 43 & 47 & 81 & 56 & 61 \\
\hline
\end{tabular}




\section{Macrothink}

Journal of Studies in Education ISSN 2162-6952 2016, Vol. 6, No. 3

Student achievement in reading, mathematics, and reading and mathematics combined as measured by the State of Texas Academic Achievement Readiness (STARR) is displayed in Table 2.

Table 2. STAAR Student Achievement Scores in Reading, Mathematics, and Reading and Mathematics Combined by Campus

\begin{tabular}{|c|c|c|c|}
\hline CODE & Reading & Math & $\mathbf{R} \& \mathbf{M}$ \\
\hline 001 & 60 & 61 & 60 \\
\hline 002 & 56 & 70 & 63 \\
\hline 003 & 67 & 49 & 58 \\
\hline 004 & 62 & 73 & 67 \\
\hline 005 & 70 & 74 & 72 \\
\hline 006 & 69 & 74 & 72 \\
\hline 007 & 77 & 80 & 78 \\
\hline 008 & 63 & 60 & 62 \\
\hline 009 & 61 & 53 & 57 \\
\hline 010 & 57 & 65 & 59 \\
\hline 011 & 56 & 67 & 61 \\
\hline 012 & 69 & 65 & 67 \\
\hline 013 & 57 & 62 & 59 \\
\hline 014 & 66 & 65 & 66 \\
\hline 015 & 74 & 68 & 71 \\
\hline 016 & 51 & 68 & 55 \\
\hline 017 & 74 & 74 & 74 \\
\hline 018 & 62 & 71 & 65 \\
\hline 019 & 77 & 79 & 78 \\
\hline 020 & 68 & 70 & 69 \\
\hline 021 & 73 & 71 & 72 \\
\hline 022 & 67 & 62 & 64 \\
\hline 023 & 72 & 69 & 70 \\
\hline 024 & 61 & 52 & 57 \\
\hline 025 & 61 & 62 & 61 \\
\hline 026 & 84 & 97 & 87 \\
\hline 027 & 67 & 64 & 65 \\
\hline 028 & 71 & 68 & 69 \\
\hline 029 & 80 & 100 & 85 \\
\hline 030 & 63 & 65 & 64 \\
\hline 031 & 70 & 76 & 73 \\
\hline 032 & 77 & 71 & 74 \\
\hline 033 & 80 & 78 & 79 \\
\hline 034 & 69 & 74 & 72 \\
\hline 035 & 86 & 82 & 84 \\
\hline 036 & 71 & 63 & 67 \\
\hline
\end{tabular}


The Spearman Rho coefficient correlation was computed to determine the strength of the relationships between reading, mathematics, and reading and mathematics combined with each of the ten dimensions of Organizational Health and the Total Organizational Health $(\mathrm{OH})$ scores. The results are displayed in Table 3.

Table 3. Relationships between Organizational Health and Achievement in Reading, Mathematics, and Reading and Mathematics combined: Spearman Rho Correlations and Descriptive Statistics $(\mathrm{N}=36)$

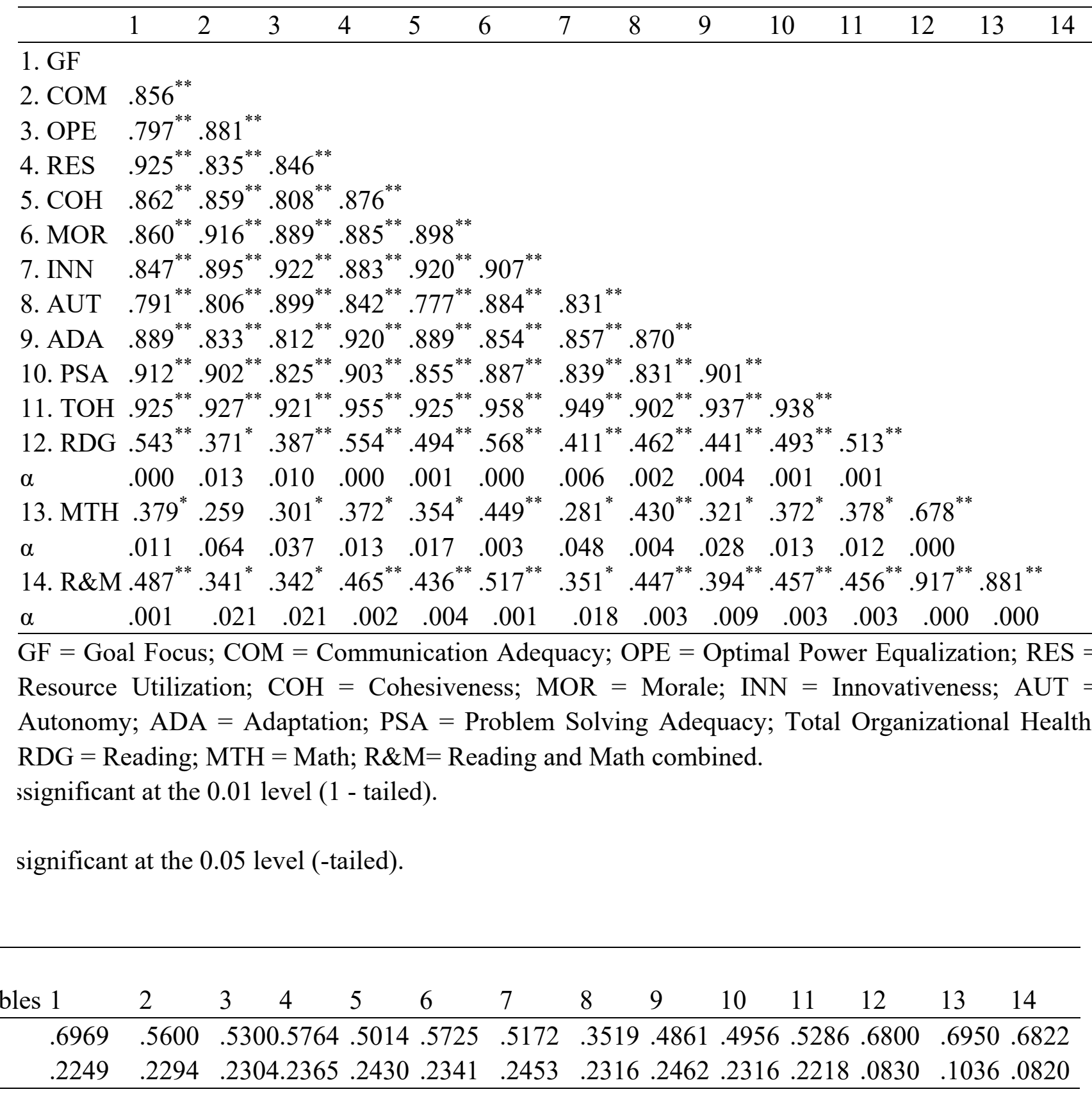

Results reject $\mathrm{H}_{0 .} 1$ and support $\mathrm{H}_{1}$.1. A positive relationship exists between reading and each of the ten dimensions of Organizational Health. The strongest relationships between Reading achievement and the ten $\mathrm{OH}$ dimensions exist with Morale, Resource Utilization, and Goal Focus. Relationships are significant at the .01 level for all dimensions, except Communications, 
which is significant at the .05 level. A positive relationship exists between total $\mathrm{OH}$ scores and student achievement in reading $r(36)=.513, p<.01$.

Results reject $\mathrm{H}_{0.2}$ and support $\mathrm{H}_{1}$. . A positive relationship exists between achievement in mathematics and nine of the ten dimensions of Organizational Health. The relationship between Total Organizational Health (Total $\mathrm{OH}$ ) and Mathematicsis significant at the .05 level. The strongest relationship between achievement in mathematics and the ten $\mathrm{OH}$ dimensions exist with Morale, Autonomy and Goal Focus. These relationships are significant at the .01 level. All dimensions are significant at the .05 level except for communication adequacy $r(36)=.259, p$ $=.064$. A positive relationship exists between total $\mathrm{OH}$ scores and student achievement in mathematics $r(36)=.378, p<.05$.

Results reject $\mathrm{H}_{0.3}$ and support $\mathrm{H}_{1} 3$. A positive relationship exists between reading and mathematics combined and each of the ten Organizational Health dimensions and the Total Organizational Health score. The relationship between Reading and Math combined and Total Organizational Health score is significant at the .01 level. The strongest relationships between achievement in Reading and Mathematics combined and the ten $\mathrm{OH}$ dimensions exist with Morale, Goal Focus, and Resource Utilization. These relationships are significant at the .01 level. A positive relationship exists between total $\mathrm{OH}$ scores and student achievement in reading and mathematics combined $r(36)=.456, p<.01$.

Overall, the results indicate there is a positive relationship between the dimensions of Organizational Health and student achievement in reading, mathematics, and reading and mathematics combined. Morale and Goal Focus had the strongest relationship with all three achievement areas.

\section{Implications}

The findings of this study indicate there is a positive relationship between Organizational Health and student achievement and are consistent with the literature (Fairman \& McLean, 2014; Roney, 2011; Barth, 2001; Uline, Miller, \& Teschanen - Moran, 1998; Hoy, 1990). Prior research by Hoy (1991) and the work of Fairman and McLean (2014) have provided evidence that organizational health supports student achievement.

This study establishes the relationship between organizational health and student achievement in a high needs district in which the student population is $95 \%$ economically disadvantaged, 99\% are Hispanic and 48\% are English Language Learners(TEA, 2013-2014 PEIMS Data).

These results suggest that all dimensions of organizational health, especially morale, goal focus, and resource utilization are important for improving student achievement. Based on results of this study, it is essential that school leaders create structures and implement processes that impact the organizational health of their schools. Attempts by school leaders to institute initiatives designed to improve student achievement should be coupled with deliberate strategies and processes to improve the organizational health of their schools.

Emphasis must be given to improve Morale, Goal Focus, Resource Utilization, Autonomy, and Problem-Solving Adequacy because the results indicate that these dimensions have the 
highest relationship to student achievement. Improving Morale will create a greater sense of well-being and satisfaction as a member of an organization contributing to goal attainment. Attention to Goal Focus will foster acceptance, support and advocacy for goals developed to improve student achievement. Appropriate use of employee knowledge and skills is required to improve Resource Utilization and minimizes the sense of strain to personnel. Providing individuals the opportunities to make decisions pertaining to their roles and responsibilities will increase Autonomy. Autonomy is highly individualized. The level of autonomy granted individuals is dependent upon their level of competency and commitment pertaining to the tasks to be performed. To address Problem-solving Adequacy, structures and processes should be instituted to address, on a timely basis, concerns and issues that arise. Solving concerns and issues on a timely basis will enhance other dimensions.

\section{Conclusions}

The researchers of this study concur with Fairman and McLean's findings that there is a relationship between the organizational health of a school and its student achievement. Given the results of this study indicating the positive relationship between organizational health and the achievement of students, these researchers propose that effective implementation of structures, systems, strategies, and leadership styles associated with the $\mathrm{OH}$ dimensions will facilitate creation of healthy schools needed to close achievement gaps. A healthy school is better able to focus on enhancing the teaching and learning environment and achievement of all students.

In The McKinsey Report (2007), Barber and Mourshed state that "All the top-performing systems recognize that they cannot improve what they do not measure" (p.52). Therefore, it is imperative that leaders measure their schools' organizational health and intentionally act to improve the internal dynamics of the school.

\section{References}

Argyris, C. (1990). Integrating the individual and the organization. New Brunswick, NJ: Transaction Publishers. (Originally published New York, NY: Wiley, 1964)

Barber, M. \& Mourshed, M. (2007). How the world's best performing school systems come out on top. New York, NY: McKinsey \& Company

Barth, J. J. (2001). Morgantown, West Virginia: West Virginia University, Department of Educational Studies.

Bennis, W. G., (1966). Changing organizations: Essays on the development and evolution of human organization. New York, NY: McGraw Hill, Inc.

Black, M. (1961). The social theories of Talcott Parsons: A critical examination. Englewood Cliffs, NJ: Harvard University Press.

Clark, E. F. (1983, September). Organizational health: A significant force in planned change. NASSP Bulletin, 67(464), 108-113. http://dx.doi.org/10.1177/019263658306746423 
Conway, J. A. (1985). A perspective on organizational cultures and organizational belief structure. The University Council for Educational Administration, 4, 7-23. http://dx.doi.org/10.1177/0013161x85021004003

Deal, T. E. \& Kennedy, A. A. (1984). Corporate cultures: The rites and ritual of corporate life. Reading, MA: Addison-Wesley.

Deal, T. E. \& Kennedy, A. A. (1992). Leadership in a world of change. In S. D. Thomson (Ed.), School leadership: A blueprint for change. Newbury Park, CA: Corwin Press.

Etzioni, A. (1975). A comparative analysis of complex organizations. New York, NY: Free Press.

Every student Succeeds Act of 2015, P.L. 114-95, Sec. 1111 State Plan (b) Challenging academic standards and academic assessments standards (2) Academic assessments (A) In general.

Every student Succeeds Act of 2015, P.L. 114-95, Sec. 1111 State Plan (c) Statewide accountability system (2) Subgroup of students.

Fairman, M., \& McLean (2011). Enhancing leadership effectiveness (2 ${ }^{\text {nd }}$ ed.). North Little Rock, AR: Paradigm Media Publishing.

Fairman, M. (2014). Organizational health individualized report. Lenexa, KS: Organizational Health: Diagnostic and Development Corporation.

Fairman, M. (2015). Special Instructions for Administering and Returning the Organizational Health

Instruments. Organizational Health: Diagnostic and Development Corporation, Lewisville, Tx.

Gonder, P. (1994). Improving school climate and culture. American Association of School Administrators, Issues Report No. 27, Arlington, VA.

Hoy, W. K. (1990, August). Organizational climate, school health, and effectiveness: A comparative analysis, Educational Administration Quarterly, 26(3), 260 - 27. http://dx.doi.org/10.1177/0013161X90026003004

Hoy, W. K. (1991). Open schools, healthy schools: Measuring organizational climate. London: Sage Publications, Inc.

Hoy, W. K. (1997, August 1). Middle school climate: An empirical assessment of organizational health and student achievement. Educational Administration Quarterly, 33(3), 290-311. http://dx.doi.org/10.1177/0013161X97033003003

Hoy, W. K., \& Miskel, C. G. (1991). Educational administration (4 ${ }^{\text {th }}$ ed.). New York, NY: McGraw-Hill Companies, Inc.

Hoy, W. K. \& Miskel, C. G. (2001 ). Educational administration (6 ${ }^{\text {th }}$ ed.). New York, NY: McGraw-Hill Companies, Inc. 
Johnstone, W. G. (1988). Organizational health instrument technical manual. Fayetteville, AK: Organizational Health, Diagnostic and Development Corp.

Miles, M. (1965). Planned change and organizational change. In R. O. Carlson, Planned change and organizational health: Figure and ground ( $3^{\text {rd }}$ Ed, 1965). Eugene, OR: University of Oregon Press.Retrieved fromhttp://files.eric.ed.gov/fulltext/ED014123.pdf

Miles, Matthew B. (1971). "Planned change and organizational health: Figure and ground." In Administering Human Resources, edited by Francis M. Trusty. Berkeley, CA.

Moorehead, G. \& Griffin, R. W. (1992). Organizational behavior. ( ${ }^{\text {rd }}$ Ed.). Dallas, TX:

Houghton Mifflin.

No Child Left Behind Act of 2001, P.L. 107-110, $107^{\text {th }}$ Congress, Title I - Improving the Academic Achievement of the Disadvantaged, 20 U.S.C. $\S 1001$ Statement of Purpose (3), (January 8, 2002).

No Child Left Behind Act, Sec 1111. State Plans (b) Academic Standards, Academic Assessments, and Accountability, (2001)

Ouchi, W. G. \& Wilkins, A. L. (1985). Organizational culture. Annual review of Sociology, 11, 457-483. http://dx.doi.org/10.1146/annurev.so.11.080185.002325

Parsons, T. (1967). Some ingredients of a general theory of formal organization. In A. Halpin, Administrative theory in education. New York, NY: Macmillan.

Pettigrew, A. M. (1979). On studying organization cultures. Administrative Science Quarterly, 24, 574. http://dx.doi.org/10.2307/2392363

Roney, K. \&. (2011). Relationship between organizational health of middle schools and student achievement in reading and math: What middle grades principals should hear. National Forum of Educational Administration and Supervision Journal, 28(4), 1-27.

Schein, E. (1983, Summer). The role of the founder in creating an organizational culture. Organization Dynamics, 13-28. http://dx.doi.org/10.1016/0090-2616(83)90023-2

Schein, E. (1985). Organizational culture and leadership. San Francisco, CA: Jossey-Bass.

Schein, E. (2010). Organizational culture and leadership. San Francisco, CA: Jossey- Bass.

Stonich. P. J. (1982). Implementing strategy: Making strategy happen. Cambridge, MA: Ballinger.

Tableman, B. (2004). School climate and learning: Best practice briefs, University-Community Partnerships at Michigan State University, No. 31, December. East Lansing: MI University-Community Partnerships, Michigan State University, Kellogg Center.

Texas Education Agency (2014). Public Education Information Management System Report, Texas Education Agency, Austin, TX. 


\section{Macrothink}

Journal of Studies in Education

ISSN 2162-6952

Texas Education Agency, (2015). 2015 Accountability Manual, Texas Education Agency, Austin, TX.

Texas Education Agency, (2015). Texas Academic Performance Reports, Texas Education Agency, Austin, TX.

Thernstrom, S. (2003). No excuses: Closing the racial gap in learning. New York, NY: Simon $\&$ Schuster.

Uline C. L., Miller D. M., \& Tschenan-Moran, M. (1998, Oct.). School effectiveness: The underlying dimensions. Educational Administration Quarterly, 34(4), 462-483. http://dx.doi.org/10.1177/0013161X98034004002 